\title{
Calculating AMBU Bag Dimensions for Use in Portable Ventilators
}

Camden Smith

University of South Florida, cmsmith11@usf.edu

Advisors:

Arcadii Grinshpan, Mathematics and Statistics

Stephen Sundarrao, Mechanical Engineering

Problem Suggested By: Stephen Sundarrao

Field of Study for Problem Suggester: Mechanical Engineering

Follow this and additional works at: https://digitalcommons.usf.edu/ujmm

Part of the Mathematics Commons

UJMM is an open access journal, free to authors and readers, and relies on your support:

Donate Now

\section{Recommended Citation}

Smith, Camden (2020) "Calculating AMBU Bag Dimensions for Use in Portable Ventilators," Undergraduate Journal of Mathematical Modeling: One + Two: Vol. 11: Iss. 1, Article 4.

DOI: https://doi.org/10.5038/2326-3652.11.1.4923

Available at: https://digitalcommons.usf.edu/ujmm/vol11/iss1/4 


\title{
Calculating AMBU Bag Dimensions for Use in Portable Ventilators
}

\begin{abstract}
Based on the design of non-portable ventilators, this project examines and analyzes the primary individual component used within a motorized $\mathrm{AMBU}$ bag ventilator - the AMBU bag. Calculations are conducted to assess the minimum volume for an AMBU bag to provide sufficient oxygen for average total lung capacity. It allows to determine the feasibility and effectiveness of an electrical, portable AMBU bag ventilator under the reduced size requirements. A calculus-based formula, known as the Disk Method, is utilized for these calculations. It is shown that the Disk method can be reversed to find a shape of an AMBU bag given a predetermined volume and desired dimensions. Thus an affordable, motorized, portable AMBU bag ventilator with full functionality and effectiveness can be developed. It will contribute to fulfilling the need for more ventilators due the current COVID-19 pandemic.
\end{abstract}

Keywords

portable ventilators, AMBU bag, lung capacity, disk method, washer method

Creative Commons License

(c) (i) (3)

This work is licensed under a Creative Commons Attribution-Noncommercial-Share Alike 4.0 License. 


\section{PROBLEM STATEMENT}

The purpose of this project is to identify feasible solutions to address the need for affordable, effective, user-friendly, portable ventilators. Solving this problem will minimize restrictions for those with conditions that affect the lungs, including acute respiratory failure, and contribute to fulfilling the need for more ventilators due the current COVID-19 pandemic.

\section{MOTIVATION}

\section{Background}

Artificial Manual Breathing Unit (AMBU) bags are commonly used to treat patients with breathing issues. The bag is manually squeezed, by a medical professional, to force oxygen into the lungs of the patient. AMBU bags are typically used at the scene of emergencies and during transport of a patient to a hospital. They are also used for respirating patients when moving them from one location to another. Hospitalized patients are usually placed on a respirator or ventilator for assistance with breathing. Currently, motorized AMBU bags are being developed and tested as an alternative to mechanical ventilators (Bergman, 2020).

\section{Problem}

Mechanical ventilators are restrictive due to their size, cost, and need for placement and monitoring by trained medical staff. Currently, the demand for ventilators has increased dramatically due the current COVID-19 pandemic. Typical mechanical ventilators are expensive at nearly $\$ 30,000$ per unit (Chandler, 2020) and take time to produce. One alternative to mechanical ventilation is the affordable and readily available AMBU Bag. However, nonmechanical AMBU bags require constant manual pressure to get oxygen to the lungs. This must be done by a skilled professional who is trained to evaluate the patient and adjust the timing and 
pressure of the pumping according to the needs and lung capacity of the patient. (Chandler, 2020).

AMBU bags are imprecise, and problems can arise because they inflate the lungs by manual force. Possible complications include lung injuries from over-inflating or over pressurization. Over-stretched lungs can lead to adult respiratory distress syndrome (ARDS) which requires mechanical ventilator support in a hospital intensive care unit. Patients may also experience hyperventilation when administered too many breaths per minute or breaths that are too large (Teschler, 2020).

\section{Project Objective}

The motivation behind this project is to determine the feasibility of developing an affordable, portable motorized AMBU bag ventilator with full functionality and effectiveness. This is the first step in identifying solutions to address the need for affordable, effective, userfriendly, portable ventilators. Solving this problem will minimize restrictions for the people with conditions that affect the lungs, including acute respiratory failure, and contribute to fulfilling the need for more ventilators due the current COVID-19 pandemic.

A portable, motorized AMBU bag ventilator may also be used in countless other scenarios. For example, this device may be an alternative for use by paramedics. Effectively regulated devices may reduce the risk of overinflating the patient's lungs and allow the paramedic to attend to other injuries rather than squeezing the AMBU bag. The device has potential to be independently operated by caregivers and high-functioning people with breathing disabilities outside of a medical facility.

Our goal is to analyze the AMBU bag component of motorized AMBU bag ventilators and calculate the dimensions of an AMBU bag so that it can meet any plausible dimensional 
requirements. This will be determined by the Disk Method. We use this method in reverse to determine a volume and desired shape and dimensions of the AMBU bag.

\section{MATHEMATICAL DESCRIPTION AND SOLUTION APPROACH}

An AMBU bag is a piece of equipment within a ventilator that inflates with a certain volume of oxygen that is compressed or squeezed with a certain amount of pressure in order to create the necessary flow rate of air into the lungs of the patient. An example of an AMBU bag within a prototype portable ventilator can be seen in Figure 1. The yellow piece, in the center of the machine, is the AMBU bag.

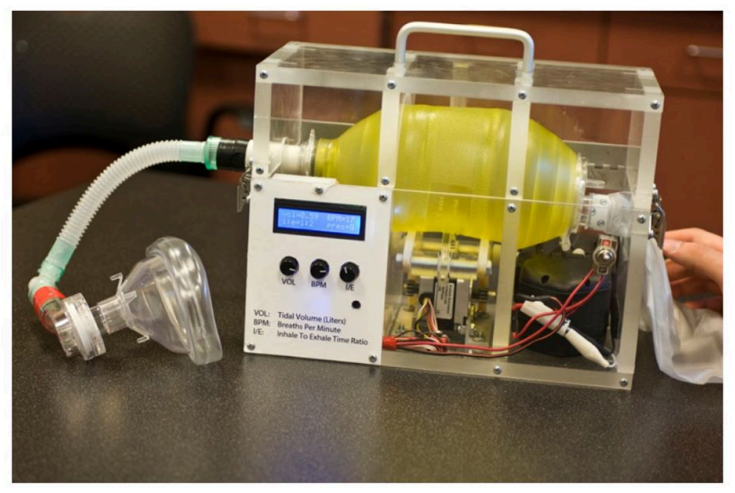

Figure 1. Prototype AMBU bag portable ventilator (Source: DeDecker, 2020)

\section{Lung Capacity}

To properly consider the minimum necessary volume required for the AMBU bag to ventilate to entire lung capacity, we first calculate the average total lung capacity. Total Lung Capacity (TLC) is calculated with a series of components, such as Inspiratory Reserve Volume (IRV), Expiratory Reserve Volume (ERV), Tidal Volume (TV), and Residual Volume (RV) (Delgado \& Tushar, 2019). We combine these components to get the TLC:

$$
\mathrm{TLC}=\mathrm{RV}+\mathrm{IRV}+\mathrm{TV}+\mathrm{ERV}
$$


There are four volumes associated with pulmonary respiration (Carroll, 2007). Inspiratory reserve volume (IRV) is the maximum amount of additional air that can be inspired at the end of a normal inspiration. Expiratory reserve volume (ERV) is the maximum volume of additional air that can be expired at the end of a normal respiration. Tidal volume (TV) is the amount of gas inspired or expired with each breath and residual volume (RV) is the volume of air remaining in the lungs after a maximum expiration. The standard values for these components associated with the average human-being are:

\begin{tabular}{l|l|l|l}
$\mathrm{IRV}=2500 \mathrm{ml}$ & $\mathrm{ERV}=1500 \mathrm{ml}$ & $\mathrm{TV}=500 \mathrm{ml}$ & $\mathrm{RV}=1500 \mathrm{ml}$
\end{tabular}

These values, when plugged in the formula to solve TLC result in:

$$
\begin{aligned}
\mathrm{TLC} & =\mathrm{RV}+\mathrm{IRV}+\mathrm{ERV}+\mathrm{TV} \\
& =(1500 \mathrm{ml})+(2500 \mathrm{ml})+(1500 \mathrm{ml})+(500 \mathrm{ml}) \\
& =6000 \mathrm{ml}
\end{aligned}
$$

The average TLC for a human is $6000 \mathrm{ml}$, that means the minimum volume required for the AMBU bag to provide a sufficient air supply to the majority of people, as well as provide the correct volume of air required to satisfy the ventilation requirements for the majority of respiratory failures (Quanjer et al., 1993).

\section{TLC AMBU bag:}

Figure 2. Graphical AMBU Bag

$\underline{\text { Key }}$

Width of pipe $=2 \mathrm{~cm}$

- $\quad$ Length of AMBU bag $=20 \mathrm{~cm}$

Height of pipe $=4 \mathrm{~cm}$

Height of $\mathrm{AMBU}$ bag $=2 \mathrm{c}=12 \mathrm{~cm}$

Note: All dimensions and assumptions made regarding this graph, are made assuming the units of the $\mathrm{x}$ axis and $\mathrm{y}$ axis are increasing by $1 \mathrm{~cm}$. 
To come up with the dimensions of an AMBU bag that has a volume equal to the TLC or $6000 \mathrm{ml}$, we reverse the Disk Method. The Disk Method is essentially an integration tool used to find the volume of an object using half the objects cross-section and revolving about an axis. The Disk Method allows for the determination of the volume of a symmetrical object using a formula that involves the "curvature" of the object. The formula for the Disk Method is:

$$
\mathrm{V}=\pi \int_{\alpha}^{\beta}[f(x)]^{2} \mathrm{~d} x
$$

This function uses definite integrals, bounded by the interval $\alpha$ to $\beta$, to find the area under a curve (i.e. the half cross-section of the object), then half cross-section is revolved around the $x$ axis through the use of $\pi r^{2}$ or the formula for an area of a circle, allowing us to end up with a volume for the solid that is created. Thus we can determine a convex function for the red dotted line in Figure 2, and this function will allow us to determine the necessary dimensions of the AMBU bag. To make this process easier, we determine the volume of the two identical pipes on either side of the AMBU bag and then subtract this from the overall volume. In order to do this, we pre-determine the desired width of our AMBU bag, plus its pipes, as well as the diameter of the pipes. The desired dimensions are listed below, as well as displayed in Figure 2. These dimensions are determined assuming a small enough size so that the machine would be easily portable:

- $\quad$ Length of $\mathrm{AMBU}$ bag $=20 \mathrm{~cm}$

- Length/Height of pipes $(\mathrm{h})=2 \mathrm{~cm}$

- $\quad$ Diameter of pipes $(2 \mathrm{r})=4 \mathrm{~cm}$

- Graphical interval of AMBU bag length $(\alpha, \beta)=[-10,10]$ 
Plugging in all the dimensions we know, as well as adding the volume of a cylinder to determine the volume of the pipes, we get the equation:

$$
\begin{gathered}
\text { TLC }=\left(\pi \int_{\alpha}^{\beta}[f(x)]^{2} \mathrm{~d} x\right)+2\left(\pi \mathrm{r}^{2} \mathrm{~h}\right) \\
6000 \mathrm{~cm}^{3}=\left(\pi \int_{-10}^{10}[f(x)]^{2} \mathrm{~d} x\right)+2\left(\pi(2 \mathrm{~cm})^{2}(2 \mathrm{~cm})\right) \\
6000 \mathrm{~cm}^{3}=\left(\pi \int_{-10}^{10}[f(x)]^{2} \mathrm{~d} x\right)+16 \pi \mathrm{cm}^{3} \\
5949.735 \mathrm{~cm}^{3}=\pi \int_{-10}^{10}[f(x)]^{2} \mathrm{~d} x \\
1893.859 \mathrm{~cm}^{3}=\int_{-10}^{10}[f(x)]^{2} \mathrm{~d} x
\end{gathered}
$$

Unfortunately, this is as far as we can go concerning the Disk Method without knowing $f(x)$. Now we take into consideration the factors about $f(x)$ that we know, and use them, along with trial and error to come up with a function that is nearly identical to $f(x)$. The factors we do know about $f(x)$ which is supposed to be even and convex are listed below:

- $f(x)$ intersects the $x$-axis and $f(x)=0$ when $x=-10$ and 10

- $f(x)$ intersects the $y$-axis, when $x=0$

- $f(x)$ can be displayed as a negative parabola / negative quadratic function

- the $y$-intercept of $f(x)$ is greater than 0

Understanding these factors, we can analyze the final point to come up with a set of basic formulas for the function $f(x)$ in a quadratic case, which involves three constants: 


$$
f(x)=-a x^{2}+b x+c
$$

where $\mathrm{b}$ determines the shift of the parabola, and $\mathrm{c}$ is the $y$-intercept of the equation.

With the previously listed conditions we know that the function $f(x)$ is equal to zero when the variable $x$ is equal to 10 or $-10:-a(-10)^{2}+b(-10)+c=-a(10)^{2}+b(10)+c=0$.

We can put the value of $b$ to be zero, as we do not want our object to be shifted on the graph but prefer it to be centered. We also can predetermine our desired height of the AMBU bag, and half of this height will give us the height of our cross-section, equal to the variable c. For example, we will use a height of $12 \mathrm{~cm}$ for our AMBU bag, giving us a value of $\mathrm{c}=6 \mathrm{~cm}$. Now we have:

$$
f(x)=-a x^{2}+6,
$$

and can easily solve for the variable a, as shown below:

$$
0=-\mathrm{a}( \pm 10)^{2}+6
$$

Hence $\mathrm{a}=0.06$.

\section{MATHEMATICAL RESUlTS FOR THE DETERMINED PROCESS}

Now we have all the necessary formulas to produce an AMBU bag that meets certain specified dimensions and can hold any specified volume in the simplest quadratic case:

- Base formula:

$$
\text { Desired Volume } V=\left(\pi \int_{\alpha}^{\beta}\left(-a x^{2}+c\right)^{2} d x\right)+2\left(\pi r^{2} h\right)
$$

- Function for the "curvature" of the AMBU bag:

$$
f(x)=-a x^{2}+c
$$

- Function for the volume of the AMBU bag: 


$$
\pi \int_{a}^{b}\left(-a x^{2}+c\right)^{2} d x
$$

- Function for the volume of the pipes:

$$
2\left(\pi r^{2} h\right)
$$

When all formulas are put together and the desired dimensions are set, we are left with resulting process:

1) Set up the base formula for an AMBU bag:

$$
\text { Desired volume } V=\left(\pi \int_{\alpha}^{\beta}\left(-a x^{2}+c\right)^{2} d x\right)+2\left(\pi r^{2} h\right)
$$

2) Select the desired dimensions:

- $\quad$ Length of AMBU bag $=(\beta-\alpha)$

- $\quad$ Length/Height of pipes $=\mathrm{h}$

- $\quad$ Radius of pipes $=\mathrm{r}$

- $\quad$ Graphical interval of AMBU bag length $=[\alpha, \beta]$

- Be sure that $\alpha$ and $\beta$ are equidistant from the origin to ensure a symmetrical

$$
\text { AMBU bag. (i.e. } \alpha=-\beta \text { : }[-1,1],[-6,6],[-10,10] \text {, etc.) }
$$

- Desired volume

- Height/thickness of AMBU bag $=2 \mathrm{c}$

3) Solve $f(x)$ for the variable a, by plugging in $\alpha$ or $\beta$ for $x$ and setting $f(x)=0$ :

$$
0=-\mathrm{a}( \pm \alpha \text { or } \pm \beta)^{2}+\mathrm{c}
$$

4) Finally, solve the right side of the base formula with all variables plugged in to verify that the volumes match on either side of the equation. Note that there may be a very minor variation 
in the volume determined by the simplification of the right side of the base formula, dependent upon the extent to which the numbers are rounded throughout simplification.

\section{DISCUSSION}

The purpose of this project was to determine a process for identifying the exact desired dimensions for an AMBU bag given any desired volume of air that the bag will need to hold. The results for this project are as expected. We were successful in determining a process to find the desired dimensions and formulas required to create an AMBU bag that meets the dimensional requirements that the engineer needs, assuming these dimensions are plausible. If the selected dimensions are not plausible, the formulas will yield inconclusive results, i.e. the variables will not be capable of being solved for or the volume yielded from the right side of the base formula will be well off. If these dimensions are used exactly to create an AMBU bag, assuming the dimensions are plausible, the AMBU bag will hold almost exactly the desired volume, after accounting for any error resulting from rounding decimals. The farther off the decimals are rounded, the more accurate the volume will be.

The implications that the results of this project have on the successful creation of an affordable and effective portable motorized ventilator are very significant, as this process will now allow for the proper determination of effective sizes for the AMBU bags, thus allowing for an accurate estimation for the size of these motorized portable ventilators. The estimation for size of the ventilators will be made more accurate in time, once the size of the electronic components, box, and other parts of the portable ventilator are determined, but given that the AMBU bag is one of the largest and most central components of this kind of portable ventilator, the determination of the AMBU bag's size will make it easier for engineers to understand how to design these other components. With this process now determined, the desired dimensions of an 
AMBU bag can now be made to hold any desired volume, not just the volume for the TLC as shown throughout the demonstration. It should be noted that the size of the desired volume will influence the plausible dimensions for the AMBU bag.

\section{CONCLUSION AND RECOMMENDATIONS}

Project calculations and analyses resulted in a process for designing an AMBU bag for a portable, mechanical ventilator. We developed a process using a common calculus approach, known as the Disk Method, to find the function $f(x)$ for the "curvature" of the AMBU bag, given certain desired specifications including the volume of the hollow part of the AMBU bag, the length and height of the AMBU bag, and the height and radius of the identical pipes on either side of the AMBU bag. For this project the volume is the average total lung capacity (TLC) and the dimensions are selected based on feasible portability.

It is to be considered that this process determines dimensions for only the hollow part of the AMBU bag and pipes. There is not consideration for the volume of the added thickness of materials used to make the actual AMBU bag. For this to be done, another commonly used calculus-based approach, known as the Washer Method, is needed. It should also be considered that some results, found through this process, may require the AMBU bag to have pointed ends, rather than the usual rounded shape. In this instance, it would be required that the pipes are placed on top of the AMBU bag rather than on either end. It is recommended that this process be tested by others to determine the desired dimensions for other symmetrical objects, so long as it is understood that $f(x)$ may take a different form than the parabolic function we used for the "curvature" of the AMBU bag. The process can be easily replicated given any volume or desired dimensions and can be used to find the volume of other symmetrical objects. 


\section{NOMENCLATURE}

\begin{tabular}{|c|c|c|}
\hline $\mathrm{V}$ & Volume & $\mathrm{cm}^{3}$ \\
\hline $\mathrm{r}$ & Radius of Pipe & $\mathrm{cm}$ \\
\hline $\mathrm{h}$ & Height of Pipe & $\mathrm{cm}$ \\
\hline$\alpha$ & Left Graphical Boundary of AMBU Bag & $\mathrm{cm}$ \\
\hline$\beta$ & Right Graphical Boundary of AMBU Bag & $\mathrm{cm}$ \\
\hline $\mathrm{a}$ & Coefficient to Determine Curvature of AMBU Bag & N/A \\
\hline $\mathrm{b}$ & Coefficient to Determine the Shift of $f(x)$ & N/A \\
\hline $\mathrm{c}$ & Half of the Height of the Cross-section / $Y$-Intercept of $f(x)$ & N/A \\
\hline
\end{tabular}

- Given that $\alpha$ and or $\beta$ is substituted for the placeholder variable $x, x$ is squared in the function $f(x)$, and the integral of the function $f(x)$ results in a raised exponent, all units match up on either side of the base formula equation, with both sides resulting in a volume with the units of $\mathrm{cm}^{3}$. 


\section{REFERENCES}

Bergman, R. "US20110041852A1 - AMBU-Bag Automation System and Method - Google Patents." Patents.google.com. N. p., 2009. Web. 5 May 2020.

Carroll, Robert G. "Pulmonary System." Elsevier's Integrated Physiology (2007): 99-115. Web. 5 May 2020.

Chandler, D. "MIT-Based Team Works on Rapid Deployment of Open-Source, Low-Cost Ventilator." MIT News. N. p., 2020. Web. 5 May 2020.

De Decker, K. "Low-Cost Breathing Ventilators." Notechmagazine.com. N. p., 2020. Web. 5 May 2020.

Delgado, B. and Tushar B. "Physiology, Lung Capacity." StatPearls Publishing (2019). Web. 5 May 2020.

Quanjer, P. H. et al. "Lung Volumes and Forced Ventilatory Flows." European Respiratory Journal 6. Supplement 16 (1993): 5-40. Web. 7 May 2020.

James Stewart. Calculus: Early Transcendentals. Cengage Learning, 2016.

Teschler, L. "More Dangerous Than the Virus? Converting Manual Resuscitators to Ventilators." Testandmeasurementtips.com. N. p., 2020. Web. 5 May 2020. 